\title{
ANALISIS SISTEM ANTRIAN CALON PENUMPANG LION AIR DI BANDAR UDARA MUTIARA SIS AL-JUFRI PALU
}

\author{
V. R. Vitasari ${ }^{1}$ Rais $^{2}$, A. Sahari ${ }^{3}$ \\ 1,3Program Studi Matematika Jurusan Matematika FMIPA Universitas Tadulako \\ Jalan Soekarno-Hatta Km. 09 Tondo, Palu 94118, Indonesia \\ 2Program Studi Statistik Jurusan Matematika FMIPA Universitas Tadulako \\ Jalan Soekarno-Hatta Km. 09 Tondo, Palu 94118, Indonesia \\ vennyvs@yahoo.com¹, rais76untad@yahoo.co.id², agus_sh@yahoo.com³
}

\begin{abstract}
Line/Queue is an activity that appears caused by the number of service facilities less than the number of people who perform services. It frequently occurs in some places that require more services while lacking of facilities. In this research, the sample derived from Lion Air's passengers in Mutiara Sis Al-Jufri Airport, Palu. Here, writer took the object starting from the entrance to the examination ticket to the waiting lounge, which recently applied Single Channel Multi Phase Service mode then changed to Multi Channel Multi Phase Service Mode aiming to increase effectiveness of the queues system that occur on the research object. Based on the research result need to applied 1 (one) server in $X$-Ray to the examination ticket to the waiting lounge so the Measure of this queue mode are $P_{0}=$ probability none passengers, $L_{s}=$ average of passangers amount in the queue, $W_{s}=$ average time required in the queue, $L_{q}=$ average of passangers amount in serve and $W_{q}=$ average time required in serve getting value as like that : in the morning on 05.00-05.30 WITA $\lambda=24, \rho=1, P_{0}=0.315, L_{s}=4, W_{s}=0.315, L_{q}=$ $0, W_{q}=0$. In the day on 10.30-11.00 WITA $=21, \rho=0.875, P_{0}=0.046, L_{s}=3.5, W_{s}=0.82, L_{q}=16.23, W_{q}=$ 0.772 and in the night on 18.00-18.30 WITA $\lambda=21, \rho=0.875, P_{0}=0.046, L_{s}=3.5, W_{s}=0.82, L_{q}=16.23, W_{q}=$ 0.772 .
\end{abstract}

\section{Keywords : Multi Channel Multi Phase Service, Mutiara Sis Al-Jufri Palu Airport, Single Channel Multi Phase Service, Queue/line}

\section{ABSTRAK}

Antrian adalah suatu kegiatan yang timbul karena jumlah fasilitas pelayanan jasa lebih sedikit dibandingkan dengan jumlah orang yang melakukan pelayanan. Kegiatan antrian sering terjadi di beberapa tempat yang membutuhkan pelayanan yang lebih besar sedangkan fasilitas pelayanannya kurang. Pada penelitian ini model antrian calon penumpang maskapai penerbangan Lion Air di Bandar Udara Mutiara Sis Al-Jufri Palu mulai dari pintu masuk sampai pemeriksaan tiket menuju ruang tunggu menjadi objek penelitian penulis. Dimana sebelumnya sudah diterapkan model antrian Single Channel Multi Phase Service kemudian diubah menjadi model antrian Multi Channel Multi Phase Service dengan tujuan meningkatkan efektifitas sistem antrian yang terjadi pada objek penelitian. Berdasarkan hasil penelitian perlu ditambahkan 1 (satu) server di titik $X$-Ray sampai dengan Pemeriksaan Tiket Menuju Ruang Tunggu sehingga berdasarkan ukuran keefektifan model antrian yaitu $P_{0}=$ probabilitas tidak ada calon penumpang, $L_{s}=$ rata-rata jumlah calon penumpang dalam antrian/sistem, $W_{s}=$ 
rata-rata waktu calon penumpang dalam antrian/sistem, $L_{q}=$ rata-rata jumlah calon penumpang yang sedang dilayani dan $W_{q}=$ rata-rata waktu calon penumpang yang sedang dilayani diperoleh nilai sebagai berikut : pada pagi hari yaitu pukul 05.00-05.30 WITA $\lambda=24, \rho=1, P_{0}=0.315, L_{s}=4, W_{s}=0.315, L_{q}=0, W_{q}=0$. Pada siang hari yaitu pukul 10.30-11.00 WITA $\lambda=21, \rho=0.875, P_{0}=0.046, L_{s}=3.5, W_{s}=0.82, L_{q}=16.23, W_{q}=0.772$ dan pada malam hari yaitu pukul 18.00-18.30 WITA $\lambda=21, \rho=0.875, P_{0}=0.046, \quad L_{s}=3.5, W_{s}=0.82, L_{q}=$ $16.23, W_{q}=0.772$

Kata kunci : Antrian, Bandar Udara Mutiara Sis Al-Jufri Palu, Multi Channel Multi Phase Service, Multi Channel Single Phase Service

\section{PENDAHULUAN}

\subsection{Latar Belakang}

Antrian adalah suatu kegiatan yang timbul karena jumlah fasilitas pelayanan jasa lebih sedikit dibandingkan dengan jumlah orang yang melakukan pelayanan. Situasi menunggu juga merupakan bagian dari keadaan yang terjadi dalam kegiatan yang bersifat acak dalam suatu fasilitas pelayanan. Pelanggan datang ke tempat antrian dengan waktu yang acak, tidak teratur dan tidak dapat segera dilayani sehingga mereka harus menunggu dalam waktu yang cukup lama. (Kakiav, T.,2004).

Kegiatan antrian sering terjadi di beberapa tempat yang membutuhkan pelayanan yang lebih besar sedangkan fasilitas pelayanannya kurang. Salah satu tempat yang sering terjadi kasus antrian yaitu Bandar Udara (Bandara), dimana pihak bandara sebagai pemberi layanan harus dapat memprediksi banyaknya loket yang dibuka untuk melayani calon penumpang yang datang dengan optimal.

Sama halnya dengan Bandar Udara di Kota Palu yaitu Bandara Mutiara Sis Al-Jufri. Bandara ini memberikan berbagai fasilitas layanan antara lain loket pemeriksaan barang $(X$ Ray), loket check-in tiket dan ruang tunggu bagi calon penumpang. Mengingat Bandara Mutiara Sis Al-Jufri Palu merupakan satu-satunya Bandar Udara di Kota Palu membuat bandara ini banyak didatangi oleh masyarakat dalam maupun luar kota Palu dan loket checkin tiket yang selalu ramai oleh calon penumpang adalah loket maskapai penerbangan Lion Air. Terutama pada waktu-waktu tertentu seperti libur sekolah dan libur hari besar dimana jumlah calon penumpang mengalami kelonjakan, pihak bandara dan maskapai penerbangan Lion Air menerima lebih banyak calon penumpangnya untuk melakukan kegiatan perjalanan mereka. 


\subsection{Tujuan}

Adapun tujuan yang ingin dicapai adalah sebagai berikut:

1. Menentukan karakteristik dari model antrian di loket Lion Air Bandara Sis Al-Jufri Palu yang meliputi:

a. Tingkat kesibukan server pada loket pemeriksaan barang, loket check-in tiket untuk maskapai penerbangan Lion Air, pembayaran Airpotax dan Pemeriksaan tiket sebelum menuju pesawat di Bandara Sis Al-Jufri Palu

b. Jumlah rata-rata dalam antrian $\left(L_{q}\right)$, Jumlah rata-rata dalam antrian dalam sistem $\left(L_{s}\right)$ untuk setiap tahap pelayanan, waktu menunggu dalam antrian $\left(W_{q}\right)$, waktu menunggu dalam dalam sistem $\left(W_{s}\right)$ untuk setiap tahap pelayanan dan probabilitas (kemungkinan) antrian $\left(P_{0}\right)$ untuk setiap tahap pelayanan?

2. Menentukan jumlah server yang diperlukan di setiap tahap pelayanan di loket Lion Air Bandara Sis Al-Jufri Palu sehingga pelayanannya menjadi optimal.

\subsection{Hipotesis}

Hipotesis penelitian yang akan digunakan dalam penelitian ini yaitu:

1. Waktu kedatangan

$\mathrm{H}_{0}$ : waktu kedatangan bersifat acak

$H_{1}$ : waktu kedatangan tidak bersifat acak

Hipotesis ini akan diuji melalui uji runtun dengan taraf signifikan $5 \%$.

2. Waktu pelayanan

$H_{0}$ : waktu pelayanan mengikuti distribusi Eksponensial

$H_{1}$ : waktu pelayanan tidak mengikuti distribusi Eksponensial

Hipotesis ini akan diuji melalui Kolmogorov Smirnov satu sampel dengan taraf signifikan $5 \%$.

\subsection{Asumsi}

Asumsi yang digunakan dalam sistem antrian di loket Lion Air Bandara Mutiara Sis AlJufri Palu yaitu :

1. Sumber masukan pelanggan yang tidak terbatas

2. Disiplin antrian adalah First Come First Serve (FCFS)

3. Panjang antrian tidak terbatas

4. Tingkat kedatangan mengikuti distribusi Poisson

5. Waktu pelayanan mengikuti distribusi Eksponensial

6. Waktu antar kedatangan berdistribusi Poisson

\section{METODE PENELITIAN}




\subsection{Penentuan Karakteristik Antrian Multi Channel Single Phase Service dan Single Channel Multi Phase Service}

Penguraian untuk Multi Channel Single Phase Service dan Single Channel Multi Phase Service berbeda, dimana untuk Multi Channel Single Phase Service, jalur antrian tunggal dan terdapat dua pelayanan. Sementara untuk Single Channel Multi Phase Service, jalur antrian tunggal dan terdapat dua atau lebih pelayanan yang dilakukan secara berurutan. Proses antrian dari hasil penelitian yang telah dilakukan calon penumpang dari pintu masuk kemudian memasuki loket $X$-Ray, bergabung kedalam antrian pada loket tersebut. Kemudian calon penumpang memasuki loket check-in tiket di maskapai penerbangan Lion Air untuk menimbang dan memasukkan bagasi, lalu melakukan pembayaran Airpotax dan melakukan pemeriksaan tiket di loket pemeriksaan tiket menuju ke ruang tunggu. Proses tersebut dapat dilihat pada Gambar 1.

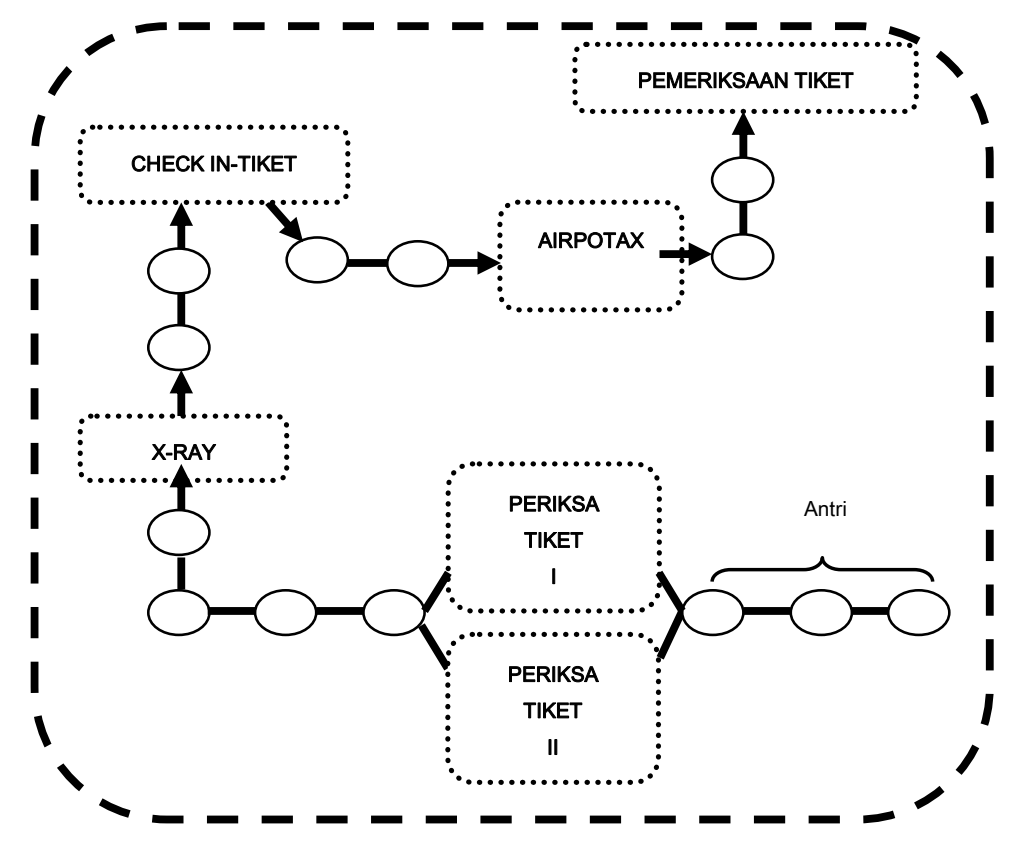

Gambar 1 : Proses antrian yang diteliti

Rumusan untuk karakteristik operasi model antrian ini dapat diuraikan dengan mengasumsikan bahwa tingkat kedatangan $(\lambda)$ dengan tingkat pelayanan $(\mu)$. Untuk mencapai keadaan Steady State, yaitu keadaan dimana analisis sistem antrian dapat digunakan maka tingkat kedatangan harus lebih kecil daripada tingkat pelayanan $(\lambda<\mu)$.

Selanjutnya untuk penguraian Single Channe/ ini, perlu digunakan rumus-rumus sebagai berikut : 
1. Tingkat Kesibukan Server (K)

Rasio antara tingkat kedatangan dengan tingkat pelayanan disebut tingkat kesibukan server $(K)$. Seorang server dikatakan sibuk apabila tingkat kesibukan server diperoleh pada kisaran lebih dari $70 \%$. Dengan rumus tingkat kesibukan server $(K)$ sebagai berikut:

$K=\frac{\lambda}{\mu}$

2. Jumlah rata-rata dalam Antrian $\left(L_{q}\right)$

Rumus untuk mengetahui jumlah rata-rata calon penumpang yang antri dalam antrian yaitu:

$L_{q}=\frac{\lambda^{2}}{\mu(\mu-\lambda)}$

3. Jumlah rata-rata dalam Sistem $\left(L_{s}\right)$

Besarnya rata-rata jumlah dalam sistem untuk model antrian ini ditentukan dengan rumus:

$L_{S}=\frac{\lambda}{(\mu-\lambda)}$

4. Waktu rata-rata menunggu dalam antrian $\left(W_{q}\right)$

Waktu rata-rata menunggu dalam antrian dapat ditentukan dengan rumus:

$W_{q}=\frac{\lambda}{\mu(\mu-\lambda)}$

5. Waktu rata-rata menunggu dalam sistem $\left(W_{s}\right)$

Rumus waktu rata-rata menunggu dalam sistem adalah:

$W_{s}=\frac{1}{\mu-\lambda}$

6. Probabilitas menunggu $\left(P_{n}\right)$

Probabilitas menunggu merupakan peluang untuk seluruh $n$ (yang antri) yang terjadi

$P_{n}=\left(\frac{\lambda}{\mu}\right)^{n}\left(1-\left(\frac{\lambda}{\mu}\right)\right)$

Dan untuk penguraian Multi Channel, digunakan rumus sebagai berikut :

1. Tingkat Kesibukan Server

$\rho=\frac{\lambda}{\mu . s}$

2. Jumlah rata-rata dalam Antrian $\left(L_{q}\right)$

Rumus untuk mengetahui jumlah rata-rata calon penumpang yang antri dalam antrian yaitu:

$L_{q}=\frac{P_{0}\left(\frac{\lambda}{\mu}\right)^{s} \rho}{s !(1-\rho)^{2}}$

3. Jumlah rata-rata dalam Sistem $\left(L_{s}\right)$ 
Besarnya rata-rata jumlah dalam sistem untuk model antrian ini ditentukan dengan rumus:

$L_{s}=L_{q}+\frac{\lambda}{\mu}$

4. Waktu rata-rata menunggu dalam antrian $\left(W_{q}\right)$

Waktu rata-rata menunggu dalam antrian dapat ditentukan dengan rumus:

$W_{q}=\frac{L_{q}}{\lambda}$

5. Waktu rata-rata menunggu dalam sistem $\left(W_{s}\right)$

Rumus waktu rata-rata menunggu dalam sistem adalah:

$W_{s}=W_{q}+\frac{1}{\lambda}$

6. Probabilitas tidak ada antrian $\left(P_{0}\right)$

$$
P_{0}=\sum_{n=0}^{s} \frac{1}{\frac{\left(\frac{\lambda}{\mu}\right)^{n}}{0 !}+\frac{\left(\frac{\lambda}{\mu}\right)^{2}}{s !\left(1-\frac{\lambda}{s \cdot \mu}\right)}}
$$

\subsection{Penentuan Karakteristik Antrian Setelah Penambahan Server}

Penambahan server dilakukaan untuk mencegah terjadinya antrian yang berkepanjangan. Untuk penambahan server otomatis model yang terjadi akan berubah. Sebelumnya model antrian yang diterapkan adalah Multi Channel Single Phase Service tetapi setelah dilakukan pengamatan, dilakukan perubahan model antrian menjadi Multi Channel Multi Phase Service. Rumus yang digunakan sama seperti sebelumnya, yang membedakan adalah jumlah server dan jumlah jalur antrian.

\subsection{Teknik Pengambilan Data}

Teknik analisa data menggunakan bantuan program SPSS 15.0 yang menganalisa data yang diperoleh terhadap waktu antar kedatangan dan waktu pelayanan. Uji dilakukan melalui Tes satu sampel Kolmogorov Smirnov yaitu suatu tes goodness of fit (tes kecocokan/kesesuaian antara distribusi serangkaian harga sampel dengan suatu distribusi teoritis tertentu). Tujuannya adalah untuk menguji hipotesis apakah sampel berasal dari suatu populasi dengan distribusi teoritis tertentu. Kolmogorov Smirnov tabel bisa diperoleh dengan rumus:

$D=\frac{1.36}{\sqrt{n}}$

dengan $n$ adalah jumlah data.

Dasar pengambilan keputusan yaitu dengan membandingkan Kolmogorov Smirnov hitung dengan Kolmogorov Smirnov tabel. Jika Kolmogorov Smirnov Hitung < Kolmogorov Smirnov Tabel, maka $H_{0}$ diterima. Nilai $D$ pada output SPSS 15.0 yakni pada keterangan ABSOLUTE, angka inilah yang disebut Kolmogorov Smirnov Hitung. 


\section{HASIL DAN PEMBAHASAN}

\subsection{Analisis dari Model Antrian}

3.1.1. Titik Pengamatan Pintu Masuk

Tabel 1 : Pengamatan Pintu Masuk dengan Satu Server

\begin{tabular}{|c|c|c|c|c|c|c|c|c|c|c|}
\hline $\begin{array}{c}\text { Waktu } \\
\text { Pengamatan }\end{array}$ & $\begin{array}{c}\text { Jumlah } \\
\text { Data }\end{array}$ & Pukul & $\lambda$ & $\mu$ & M & $P_{0}$ & $L_{s}$ & $W_{s}$ & $L_{q}$ & $W_{q}$ \\
\hline \multirow{3}{*}{ Pagi } & \multirow{9}{*}{50} & $05.00-05.30$ & 24 & 15 & 2 & 0.125 & 4.8 & 0.2 & 3.2 & 0.133 \\
\hline & & $05.30-06.00$ & 15 & 15 & 2 & 0.5 & 1.5 & 0.1 & 0.5 & 0.033 \\
\hline & & $06.00-06.30$ & 11 & 15 & 2 & 0.863 & 0.945 & 0.085 & 0.212 & 0.019 \\
\hline \multirow{3}{*}{ Siang } & & $10.00-10.30$ & 13 & 15 & 2 & 0.653 & 1.198 & 0,092 & 0.331 & 0.025 \\
\hline & & $10.30-11.00$ & 23 & 15 & 2 & 0.152 & 4.052 & 0.176 & 2.519 & 0.109 \\
\hline & & $11.00-11.30$ & 14 & 15 & 2 & 0.571 & 1.341 & 0.095 & 0.408 & 0.029 \\
\hline \multirow{3}{*}{ Malam } & & $18.00-18.30$ & 21 & 15 & 2 & 0.214 & 3,033 & 0.144 & 1.633 & 0.077 \\
\hline & & $18.30-19.00$ & 13 & 15 & 2 & 0.653 & 1.198 & 0.092 & 0.331 & 0.025 \\
\hline & & $19.00-19.30$ & 16 & 15 & 2 & 0.438 & 1.676 & 0.104 & 0.609 & 0.038 \\
\hline
\end{tabular}

(Sumber: Data Kuantitatif Calon Penumpang Lion Air)

Tabel diatas menunjukkan efektifitas nilai ukuran dari model antrian Single Channel Multi Phase Service yang diterapkan di pintu masuk. Dari tabel 1 diketahui bahwa jam sibuk server di pintu masuk pada pagi hari yaitu pada pukul 05.00-05.30 WITA, siang hari pada pukul 10.30-11.00 WITA dan malam hari pada pukul 18.0018.30. Hal itu dapat disimpulkan berdasarkan nilai $\lambda, P_{0}, L_{s}, W_{s}, L_{q}, W_{q}$ dari masingmasing waktu tersebut. Nilai $\lambda$ merepresentasikan jumlah rata-rata kedatangan calon penumpang per 30 menit. $P_{0}$ yaitu probabilitas tidak ada calon penumpang yang datang. $L_{s}$ dan $L_{q}$ adalah rata-rata calon penumpang dalam antrian/sistem dan ratarata calon penumpang yang sedang dilayani. Karena $L_{s}$ dan $L_{q}$ satuannya adalah orang, maka hasil dalam bentuk desimal harus dibulatkan. Nilai $W_{s}$ dan $W_{q}$ masingmasing menunjukkan waktu yang dibutuhkan setiap orang dalam mengantri dan waktu yang diperlukan setiap orang untuk dilayani. Satuan $\mathrm{W}_{\mathrm{s}}$ dan $\mathrm{W}_{\mathrm{q}}$ yang diperoleh dari tabel 1 masih dalam satuan detik, sehingga harus dikonversi ke dalam satuan menit. 
Tabel 2 : Pengamatan X-Ray sampai Pemeriksaan Tiket Menuju Ruang Tunggu Satu Server

\begin{tabular}{|c|c|c|c|c|c|c|c|c|c|c|}
\hline $\begin{array}{c}\text { Waktu } \\
\text { Pengamatan }\end{array}$ & $\begin{array}{l}\text { Jumla } \\
\text { h Data }\end{array}$ & Pukul & $\lambda$ & $\mu$ & $\rho$ & $P_{0}$ & $L_{s}$ & $W_{s}$ & $L_{q}$ & $W_{q}$ \\
\hline \multirow{3}{*}{ Pagi } & \multirow{9}{*}{50} & $05.00-05.30$ & 24 & 6 & 1 & 0.315 & 4 & 0.315 & 0 & 0 \\
\hline & & $05.30-06.00$ & 15 & 6 & 0.113 & 0.108 & 2.5 & 0.121 & 0.824 & 0.54 \\
\hline & & $06.00-06.30$ & 11 & 6 & 0.458 & 0.25 & 1.833 & 0.107 & 0.184 & 0.016 \\
\hline \multirow{3}{*}{ Siang } & & $10.00-10.30$ & 13 & 6 & 0.542 & 0.163 & 2.166 & 0.106 & 0.387 & 0.029 \\
\hline & & $10.30-11.00$ & 21 & 6 & 0.875 & 0.046 & 3.5 & 0.82 & 16.23 & 0.772 \\
\hline & & $11.00-11.30$ & 16 & 6 & 0.667 & 0.096 & 2.667 & 0.139 & 1.22 & 0.076 \\
\hline \multirow{3}{*}{ Malam } & & $18.00-18.30$ & 21 & 6 & 0.875 & 0.046 & 3.5 & 0.82 & 16.23 & 0.772 \\
\hline & & $18.30-19.00$ & 13 & 6 & 0.542 & 0.163 & 2.166 & 0.106 & 0.387 & 0.029 \\
\hline & & $19.00-19.30$ & 16 & 6 & 0.667 & 0.096 & 2.667 & 0.139 & 1.22 & 0.076 \\
\hline
\end{tabular}

(Sumber: Data Kuantitatif Calon Penumpang Lion Air)

Tabel diatas menunjukkan efektifitas nilai ukuran dari model antrian Single Channel Multi Phase Service yang diterapkan di X-Ray sampai Pemeriksaan Tiket Menuju Ruang Tunggu. Dari tabel 2 diketahui bahwa jam sibuk server di X-Ray sampai Pemeriksaan Tiket Menuju Ruang Tunggu sama dengan jam sibuk pada Pintu Masuk. Akan tetapi nilai $\lambda, P_{0}, L_{s}, W_{S}, L_{q}, W_{q}$ dari masing-masing waktu tersebut berbeda dengan nila-nilai pada pintu masuk.

\subsection{Analisis Model Antrian Setelah Penambahan Server}

\subsubsection{Titik Pengamatan Pintu Masuk}

Pada tabel 1 terlihat bahwa jumlah server pada titik pengamatan Pintu Masuk sudah optimal pada jam sibuk, sehingga tidak dilakukan penambahan server pada pintu masuk.

\subsubsection{Titik Pengamatan X-Ray sampai Pemeriksaan Tiket Menuju Ruang Tunggu}

Berdasarkan hasil analisis nilai-nilai yang diperoleh dari table 2, maka dapat disimpulkan bahwa perlu dilakukan penambahan server pada Titik Pengamatan XRay sampai Pemeriksaan Tiket Menuju Ruang Tunggu. Hal itu otomatis akan merubah model antrian yang sebelumnya diterapkan yaitu Multi Channel Single Phase Service menjadi Multi Channel Multi Phase Service. 
Pada titik pengamatan ini dilakukan penambahan server sebanyak 2 (dua) server untuk setiap titik pengamatan dan dapat dilihat perubahan nilai yang terjadi dari tabel 2 menjadi table 4 berikut.

Tabel 3 : Titik Pengamatan X-Ray sampai Pemeriksaan Tiket Menuju Ruang Tunggu Setelah Penambahan Server

\begin{tabular}{|c|c|c|c|c|c|c|c|c|c|c|}
\hline $\begin{array}{c}\text { Waktu } \\
\text { Pengamatan }\end{array}$ & $\begin{array}{c}\text { Jumlah } \\
\text { Data }\end{array}$ & Pukul & $\lambda$ & $\mu$ & $\rho$ & $P_{0}$ & $L_{s}$ & $W_{s}$ & $L_{q}$ & $W_{q}$ \\
\hline \multirow{3}{*}{ Pagi } & \multirow{9}{*}{50} & $05.00-05.30$ & 48 & 6 & 1 & 0.0005 & 0 & 0 & 0 & 0 \\
\hline & & $05.30-06.00$ & 30 & 6 & 0.625 & 0.007 & 5.311 & 0.043 & 0.311 & 0.043 \\
\hline & & $06.00-06.30$ & 22 & 6 & 0.458 & 0.025 & 3.699 & 0.046 & 0.032 & 0.001 \\
\hline \multirow{3}{*}{ Siang } & & $10.00-10.30$ & 26 & 6 & 0.542 & 0.013 & 4.441 & 0.042 & 0.108 & 0.004 \\
\hline & & $10.30-11.00$ & 42 & 6 & 0.875 & 0.001 & 17.014 & 0.262 & 10.014 & 0.238 \\
\hline & & $11.00-11.30$ & 32 & 6 & 0.667 & 0.005 & 5.851 & 0.047 & 0.517 & 0.16 \\
\hline \multirow{3}{*}{ Malam } & & $18.00-18.30$ & 42 & 6 & 0.875 & 0.001 & 17.014 & 0.262 & 10.014 & 0.238 \\
\hline & & $18.30-19.00$ & 26 & 6 & 0.542 & 0.013 & 4.441 & 0.042 & 0.108 & 0.004 \\
\hline & & $19.00-19.30$ & 32 & 6 & 0.667 & 0.005 & 5.851 & 0.047 & 0.517 & 0.16 \\
\hline
\end{tabular}

(Sumber: Data Kuantitatif Calon Penumpang Lion Air)

\section{KESIMPULAN}

Berdasarkan penelitian yang telah dilakukan dapat disimpulkan bahwa :

1. Jam sibuk server terlihat pada titik pengamatan $X$-Ray sampai dengan Pemeriksaan Tiket Menuju Ruang Tunggu pada pagi hari yaitu pukul 05.00-05.30 WITA. Terlihat dari nilai $=24, \rho=1, P_{0}=0.315, L_{s}=4, W_{s}=0.315, L_{q}=0, W_{q}=0$. Pada siang hari yaitu pukul 10.30-11.00 WITA, terlihat dari nilai $\lambda=\mathbf{2 1}, \boldsymbol{\rho}=\mathbf{0 . 8 7 5}, \boldsymbol{P}_{\mathbf{0}}=\mathbf{0 . 0 4 6}$, $L_{s}=3.5, W_{s}=0.82, L_{q}=16.23, W_{q}=0.772$. Pada malam hari yaitu pukul 18.0018.30 WITA, terlihat dari nilai $\lambda=21, \rho=0.875, P_{0}=0.046, \quad L_{s}=3.5, W_{s}=$ $0.82, L_{q}=16.23, W_{q}=0.772$

2. Berdasarkan hasil analisis jam sibuk yang telah diperoleh pada titik pengamatan $X$ Ray sampai dengan Pemeriksaan Tiket Menuju Ruang Tunggu, maka perlu dilakukan penambahan server pada jam sibuk tersebut. Untuk setiap titik pengamatan ditambahkan 1 (satu) server sehingga jumlah server dari titik pengamatan $X$-Ray sampai dengan Pemeriksaan Tiket Menuju Ruang Tunggu berjumlah 8 (delapan) server dengan hasil sebagai berikut :

- $\quad$ Pada pagi hari yaitu pukul 05.00-05.30 WITA dengan $\boldsymbol{\lambda}=\mathbf{4 8}, \boldsymbol{\rho}=\mathbf{1}, \boldsymbol{P}_{\mathbf{0}}=$ $0.0005, L_{s}=0, W_{s}=0, L_{q}=0, W_{q}=0$.

- $\quad$ Pada siang hari yaitu pukul 10.30-11.00 WITA dengan $\boldsymbol{\lambda}=\mathbf{4 2}, \boldsymbol{\rho}=\mathbf{0 . 8 7 5}, \boldsymbol{P}_{\mathbf{0}}=$ $0.001, L_{s}=17.014, W_{s}=0.262, L_{q}=10.014, W_{q}=0.238$ dan 
- Pada malam hari yaitu pukul 18.00-18.30 WITA dengan $\boldsymbol{\lambda}=\mathbf{4 2}, \boldsymbol{\rho}=$ $0.875, P_{0}=0.001, L_{s}=17.014, W_{s}=0.262, \quad L_{q}=10.014, W_{q}=0.238$

\section{DAFTAR PUSTAKA}

[1]. Aminudin., 2005, Prinsip Prinsip Riset Operasi, Erlangga, Jakarta.

[2]. Broson, R., 1996, Operation Research Teori Dan Soal-Soal, Erlangga, Jakarta.

[3]. Kakiav, T.J., 2004, Dasar Teori Antrian untuk Kehidupan Nyata, Andi, Yogyakarta.

[4]. Prawirosentano, S., 2000, Riset Operasi dan Ekonofisika, Bumi aksara, Jakarta.

[5]. Santoso, S., 2001, Statistik Non Parametrik buku Latihan SPSS, PT Alex Media Komputindo Gramedia, Jakarta.

[6]. Siagian, P., 2006, Penelitian Operasional Teori Dan Praktek, Universitas Indonesia, Jakarta.

[7]. Wijaya., 2000, Statistik Non Parametrik Aplikasi Program SPSS, Alfabeta, Bandung.

[8]. Anaviroh., 2011, Model Antrian Satu Server Dengan Pola Kedatangan Berkelompok (Batch Arrival), Universitas Negeri Yogyakarta, Yogyakarta. 